\title{
DIABETES MELLITUS E O PROCESSO DE CICATRIZAÇÃo CUTÂNEA
}

\author{
Maria Helena de Melo Lima', Eliana Pereira Araujo²
}

\begin{abstract}
RESUMO: O objetivo desta atualização foi abordar o mecanismo molecular e celular do processo de cicatrização de feridas cutâneas em indivíduos com diabetes mellitus. O processo de reparo tecidual em indivíduos com diabetes mellitus é lentificado, a produção excessiva de Espécies Reativas de Oxigênio, diminuição do Óxido Nítrico, diminuição da reposta aos Fatores de Crescimento e das proteínas da via de sinalização da insulina estão envolvidos neste processo. O sucesso no tratamento de feridas de difícil cicatrização depende do conhecimento dos fatores que interferem neste processo, que aliado à prática clínica trará ao enfermeiro subsídios para prevenção, intervenções e escolha de coberturas adequadas para o cuidado e tratamento de feridas em pacientes com diabetes mellitus.
\end{abstract}

DESCRITORES: Cicatrização; Diabetes mellitus; Enfermagem.

\section{DIABETES MELLITUS AND THE PROCESS OF CUTANEOUS HEALING}

ABSTRACT: The objective of this updating study was to address the molecular and cellular process of the healing of cutaneous wounds in individuals with diabetes mellitus. The process of tissue repair in individuals with diabetes mellitus is slowed down; the excessive production of Reactive oxygen species, the reduction of Nitric Oxide, the reduction in the response to Growth Factors and the reduction in the proteins of the insulin signalling route are all involved in this process. Success in treating wounds which are having difficulty in healing depends on knowledge of the factors which interfere in this process, which, allied with clinical practice, provides the nurse with support for prevention, interventions and choice of appropriate dressings for the care and treatment of wounds in patients with diabetes mellitus.

DESCRIPTORS: Healing; Diabetes mellitus; Nursing.

\section{DIABETES MELLITUS Y EL PROCESO DE CICATRIZACIÓN CUTÁNEA}

RESUMEN: La finalidad de esta actualización fue plantear el mecanismo molecular y celular del proceso de cicatrización de heridas cutáneas en individuos con diabetes mellitus. El proceso de restauración tecidual en individuos con diabetes mellitus es lentificado, la producción excesiva de Especies Reactivas de Oxigenio, reducción del Óxido Nítrico, reducción de la respuesta a los Factores de Crecimiento y de las proteínas de la vía de señalización de la insulina hacen parte de este proceso. El éxito en el tratamiento de heridas de dificil cicatrización depende del conocimiento de los factores que interfieren en este proceso, lo cual junto a la práctica clínica traerá al enfermero subsidios para prevención, intervenciones y elección de medidas adecuadas para el cuidado y tratamiento de heridas en pacientes con diabetes mellitus.

DESCRIPTORES: Cicatrización; Diabetes mellitus; Enfermería.

${ }^{1}$ Enfermeira. Doutora em Enfermagem. Professora do Curso de Graduação e do Programa de Pós-Graduação em Ciências da Saúde da Faculdade de Enfermagem da Universidade Estadual de Campinas - UNICAMP. Líder do Grupo de Pesquisa Mecanismos Moleculares da Cicatrização de Lesões.

${ }^{2}$ Enfermeira. Doutora em Fisiopatologia Médica. Professora do Curso de Graduação e do Programa de Pós-Graduação em Ciências da Saúde da Faculdade de Enfermagem da UNICAMP.

Autor correspondente:

Recebido: $13 / 11 / 2012$

Maria Helena de Melo Lima Aprovado: 23/01/2013

Universidade Estadual de Campinas

R. Tessália Vieira de Camargo, 126 - 13083-887 - Campinas-SP-Brasil

E-mail: melolima@fcm.unicamp.br

Cogitare Enferm. 2013 Jan/Mar; 18(1):170-2 


\section{INTRODUÇÃO}

O surgimento de uma ferida em um organismo desencadeia uma cascata de reações celulares e bioquímicas com objetivo de reparar o tecido lesionado. Em pacientes diabéticos, este reparo é lentificado. Vários mecanismos são apontados como fatores importantes na diminuição do processo de cicatrização, entre eles, a produção excessiva de Espécies Reativas de Oxigênio (ROS), diminuição do Óxido Nítrico (NO), diminuição da reposta aos Fatores de Crescimento (GFs) e das proteínas da via de sinalização da insulina ${ }^{(1-2)}$.

A presença da disfunção endotelial, caracterizada pela incapacidade das artérias e arteríolas em desempenhar suas funções na regulação do tônus vascular, em resposta a um estímulo apropriado, leva a um microambiente isquêmico. Esta disfunção está associada com a diminuição da biodisponibilidade do NO, pela diminuição da produção pelo endotélio e/ou aumentada inativação do NO por $\operatorname{ROS}^{(3)}$. A excessiva produção de ROS em pacientes diabéticos é um fator primário que contribui para deficiências de cicatrização de feridas. Estudo demonstrou que a cicatrização de feridas e a angiogênese são prejudicadas pela redução de NO dependente de NOS induzível (iNOS), que também interfere na expressão de $\mathrm{GFs}^{(3)}$. Outro aspecto importante é que o Óxido Nítrico Endotelial (eNOS) é capaz de ativar a mobilização de Derivados Endoteliais de Células Progenitoras da Medula Óssea (EPCs) para o leito da ferida. Estas células desempenham uma função importante no processo de neovascularização ${ }^{(4)}$.

O rompimento do equilibrio normal das Metaloproteinases (MMPs) e dos Inibidores Teciduais da Metaloproteinases (TIMPs) também contribui para o retardo da cicatrização em diabéticos ${ }^{(5)}$. Dois tipos de MMPs, a 9 e a 2 , foram descritas como aumentadas em feridas, ao passo que há diminuição relativa de $\operatorname{TIMPs}^{(3)}$. O aumento da expressão do Fator de Necrose Tumoral $\alpha(\mathrm{TNF} \alpha)$ pode reduzir a produção de TIMPs por fibroblastos, contribuindo potencialmente pela elevada atividade proteolítica nessa situação ${ }^{(2,5)}$. As TIMPs também são responsáveis por estimular o crescimento de uma variedade de tipos de células, incluindo queratinócitos e células epiteliais ${ }^{(2,5)}$. Além disso, é descrita a diminuição da expressão do Fator de Crescimento Transformador $\beta 1$ (TGF- $\beta 1$ ), um potente modulador da atividade da colagenase e da secreção de TIMPs. O TGF- $\beta 1$ também é capaz de estimular a apoptose de células epiteliais e fibroblastos, processo importante na retração da ferida, de modo que a falta deste fator de crescimento leva ao retardo da cicatrização ${ }^{(3,5)}$.
Outra via envolvida neste processo é a da sinalização da insulina, expressa na pele intacta de animais, sendo que, com o estímulo exógeno de insulina, ocorre a ativação de proteínas. Estudo ${ }^{(6)}$ recente identificou que as proteínas envolvidas na via de sinalização de insulina na ferida cutânea de animais diabéticos estão diminuídas em relação aos animais saudáveis. No entanto, quando a ferida é tratada com um creme tópico enriquecido com insulina ocorre uma aceleração do processo cicatricial, com recuperação da atividade das proteínas da via de sinalização de insulina. Proteínas envolvidas no início da cascata de sinalização da insulina, ou seja, Receptor de Insulina (IR), Substrato 1 e 2 do Receptor de Insulina (IRS-1/2), e a Serine/Treonina Quinase AKT, estão aumentadas no tecido cicatricial tratado com o creme, em comparação com os animais que não receberam o tratamento, de acordo com o estudo( ${ }^{(6)}$.

A ativação da AKT é um passo importante para a liberação de Fator de Crescimento Endotelial Vascular (VEGF) em feridas cutâneas, por meio de um mecanismo pós-transcricional em queratinócitos ${ }^{(7)}$. Portanto, o aumento desta via de sinalização, observado após o tratamento com o creme de insulina, contribui para a cicatização cutânea. O estímulo com a insulina tópica é também capaz de ativar a Proteína Quinase com Atividade Mitogênica (ERK). Através da fosforilação das Proteinas Quinases Ativadas por Mitógenos (MAPquinase), a ERK ativada se transloca para o núcleo onde catalisa a fosforilação de fatores de transcrição, o que leva à proliferação celular ou diferenciação ${ }^{(8)}$. A ERK é essencial para as vias de sinalização migratórias de queratinócitos ${ }^{(8)}$. Em estudo observou-se melhora na secreção dos GFs, como VEGF, demonstrando uma inter-relação (cross-talk) da via de sinalização da insulina e os $\mathrm{GFs}^{(6)}$.

\section{CONSIDERAÇÕES FINAIS}

Apresentamos neste artigo as principais alterações celulares e moleculares do processo de cicatrização na presença de diabetes mellitus. As células e seus sistemas mensageiros inter/intracelulares formam um sistema hierárquico com fases sobrepostas de características não lineares. Compreender os mecanismos moleculares trará, no futuro, novas estratégias para promover a cicatrização, restaurar a função da pele, bem como permitirá o emprego de novas terapias tópicas para o tratamento de feridas. Entretanto, a conduta e o tratamento de feridas devem ser acompanhados por uma equipe multiprofissional. Neste contexto, é fundamental que o enfermeiro 
esteja preparado para conduzir o preparo do leito da ferida, com a realização do desbridamento, reconhecer sinais e sintomas de infecção local e sistêmica, bem como identificar o comprometimento vascular.

O conhecimento do mecanismo molecular do processo de cicatrização, aliado à prática clínica do tratamento de feridas, trará ao enfermeiro novos investimentos na prevenção, condutas coerentes na condução do preparo do leito da ferida e escolha de coberturas adequadas.

\section{REFERÊNCIAS}

1. Brem H. Tomic-Canic M. Cellular and molecular basis of wound healing in diabetes. J. Clin Invest. 2007;117(5):1219-22.

2. Kolluru GK, Bir SC, Kevil CG. Endothelial dysfunction and diabetes: effects on angiogenesis, vascular remodeling, and wound healing. Int J Vasc Med. [Internet] 2012 [acesso em 06 nov 2012] Disponível: http://dx.doi.org/10.1155/2012/918267

3. Kaneto H, Katakami N, Matsuhisa M, Matsuoka TA. Role of reactive oxygen species in the progression of type 2 diabetes and atherosclerosis. Mediators inflamm. [Internet] 2010 [acesso em 06 nov 2012] Disponível: http:// www.hindawi.com/journals/mi/2010/453892/Article

4. Gallagher KA, Liu ZJ, Xiao M, Chen H, Goldstein LJ, Buerk DG, et al. Diabetic impairments in NOmediated endothelial progenitor cell mobilization and homing are reversed by hyperoxia and SDF- $1 \alpha$. J Clinl Invest. [Internet] 2007;117(5) [acesso em 06 nov 2012]. Disponível: http://www.ncbi.nlm.nih.gov/ pubmed/17476357

5. Martins VL, Caley M, O'Toole EA. Matrix metalloproteinases and epidermal wound repair. Cell Tissue Res. [Internet] 2013;351(2) [acesso em $02 \mathrm{fev}$ 2013] Disponivel: http://www.springerlink.com/content/ p14581xn610nh468/ DOI: 10.1007/s00441-012-1410-z

6. Lima MH, Caricilli AM, Abreu LL, Araújo EP, Pelegrinelli FF, Thirone AC, et al. Topical insulin accelerates wound healing in diabetes by enhancing the AKT and ERK pathways: A double-blind placebo-controlled clinical trial. PLoS One. [Internet] 2012;7(5) [acesso em 14 jan 2013] Disponível: http://www.plosone.org/article/authors/ info\%3Adoi\%2F10.1371\%2Fjournal.pone.0036974

7. Goren I, Müller E, Schiefelbein D, Gutwein P, Seitz $\mathrm{O}$, Pfeilschifter J, et al. Akt1 controls insulin-driven VEGF biosynthesis from keratinocytes: implications for normal and diabetes-impaired skin repair in mice. J Invest Dermatol. 2009;129(3):752-64.

8. Boulton TG, Nye SH, Robbins DJ, Ip NY, Radziejewska E, Morgenbesser SD, et al. ERKs: a family of proteinserine/threonine kinases that are activated and tyrosine phosphorylated in response to insulin and NGF. Cell. 1991;65(4):663-75.

Cogitare Enferm. 2013 Jan/Mar; 18(1):170-2 